\title{
Utilização de processo de análise hierárquica para definição estrutural e operacional de centros de distribuição: uma aplicação a uma empresa do ramo alimentício
}

\section{The use of analytic hierarchy process for the structural and operational definition of distribution centers: an application to a food company}

\author{
Carla Regina Mazia Rosa ${ }^{1}$ \\ Maria Teresinha Arns Steiner ${ }^{1}$ \\ João Carlos Colmenero ${ }^{2}$
}

\begin{abstract}
Resumo: Um dos mais importantes aspectos a ser considerado pelos Centros de Distribuição (CDs) é a melhoria do processo com relação aos atributos de seus serviços. O objetivo deste artigo é analisar várias alternativas para definição de um CD por meio da utilização de um processo multicritério de apoio à decisão, mais especificamente, o Processo de Análise Hierárquica (Analytic Hierarchy Process; AHP), para a atribuição e ponderação dos níveis de importância para a estruturação de CDs. Para melhor ilustrar o processo, fez-se uso dos dados de uma empresa multinacional do ramo alimentício. O processo permitiu identificar a melhor estrutura dentre três possíveis alternativas, que foram avaliadas a partir da definição dos critérios e subcritérios voltados a esse contexto de decisão. Os resultados obtidos mostram que os fatores "custo" e "qualidade" são os principais responsáveis para a escolha da alternativa mais adequada.
\end{abstract}

Palavras-chave: Centro de distribuição; Processo de análise hierárquica; Medidas de desempenho.

\begin{abstract}
One of the most important aspects to be considered by Distribution Centers (CDs) is the improvement of the process in relation to the attributes of their services. The purpose of this article is to analyze various alternatives for the definition of a CD with the use of a method of multicriteria decision support, more specifically, the Analytic Hierarchy Process (AHP) for the allocation and weighting of importance levels for structuring CDs. To further illustrate the process, we used the data collected in a field study carried out in a multinational company of the food sector. The process allowed us to identify the best structure among three possible alternatives that were evaluated based on the criteria and sub-criteria targeted at the decision context. The results show that cost and quality are the main factors responsible for choosing the most appropriate alternative.
\end{abstract}

Keywords: Distribution center; Analytic hierarchy process; Performance measures.

\section{Introdução}

No mercado globalizado, as empresas competem pela rapidez, flexibilidade, qualidade, custo, confiabilidade de seus produtos e serviços. As empresas têm buscado estudar formas de garantir vantagens sobre seus concorrentes para conquistar novos clientes, assim como para manter os já existentes. As empresas procuram agilidade no fluxo de materiais, pois necessitam reduzir os gastos com estoque e, para isso, é necessário estabelecer parceria com os fornecedores para que recebam e entreguem os pedidos no tempo estabelecido e com qualidade, ou seja, sem atrasos e sem defeitos, respectivamente.
A redução dos custos e a entrega no menor tempo ao cliente estão diretamente ligadas ao sistema de distribuição. Desta forma, torna-se necessário o planejamento adequado do sistema de distribuição, para suportar o crescimento das organizações de forma estruturada. Neste âmbito, as empresas se obrigam a reestruturar suas operações de armazenagem para suprir o crescente aumento no número de pedidos. Uma tática realizada é armazenar suas mercadorias em Centros de Distribuição (CDs), cujo foco principal é facilitar a entrega direta e contínua em cada ponto de venda, visando reduzir as necessidades de estoque

\footnotetext{
${ }^{1}$ Pontifícia Universidade Católica do Paraná - PUCPR, Curitiba, PR, Brasil, e-mail: carla_mazia@hotmail.com; maria.steiner@pucpr.br ${ }^{2}$ Universidade Tecnológica Federal do Paraná - UTFPR, Ponta Grossa, PR, Brasil, e-mail: colmenero@utfpr.edu.br
} 
nas empresas para obter ganhos econômicos entre o custo, a armazenagem e o transporte.

Neste sentido, as organizações estão procurando formas para melhorar seu desempenho operacional por meio de melhor integração das operações na cadeia de valor (Kueng, 2000). Schönsleben (2000) sugeriu a classificação dos indicadores em cinco amplas categorias relacionadas aos objetivos de desempenho: qualidade, rapidez, confiabilidade, flexibilidade e custo. Christopher (2011) e Dornier et al. (2011) destacaram ainda que há quatro aspectos da concorrência baseados no tempo, custo, serviço e qualidade que devem ser gerenciados de modo coerente e integrados, para que a organização seja mais ágil e tenha maior capacidade de reação e, consequentemente, mais lucrativa.

De uma forma geral, a habilidade para medir e avaliar o desempenho logístico pode ser vista como uma necessidade para as empresas, que gastam enormes recursos ao longo dos anos para desenvolver sistemas de medição para tal fim (Kueng, 2000). Os CDs também sofrem com a competitividade dos concorrentes na disputa pelo atendimento aos clientes e, por isso, é fundamental que ocorram constantes melhorias nesses sistemas. Alguns critérios, quanto à exigência do cliente, foram definidos por Vieira et al. (2009); tais critérios se referem às entregas no tempo, entregas sem erro, entregas frequentes, disponibilidade de produto e cumprimento da agenda de entrega.

Bernroider \& Stix (2007) afirmam que o uso de metodologia de análise de decisão não é muito difundido nas organizações e a elaboração de um processo apoiado em procedimentos científicos pode auxiliar no processo de decisão. A definição da estrutura de um CD é uma decisão crítica, uma vez que, tanto os custos de um sistema de distribuição como o nível de serviço fornecido ao cliente são diretamente afetados desde seu recebimento até sua expedição do produto (Huijun et al., 2008). Desta maneira, na tomada de decisão deve-se buscar a opção que proporcione o melhor processo de desempenho e, além disto, o melhor acordo entre as expectativas do decisor e as suas disponibilidades em adotá-la, considerando a relação entre elementos objetivos e subjetivos. Segundo Wang et al. (2007), o processo deverá permitir a medição da coerência dos julgamentos dos decisores.

Nesse contexto, o objetivo deste trabalho é propor uma metodologia de apoio à tomada de decisão para definição estrutural e operacional de CD no setor alimentício. No setor alimentício, os CDs devem ser estrategicamente operacionais e estruturados para atender de forma precisa seus clientes, manter a competitividade e reduzir os custos logísticos. Por isso, a escolha estrutural e operacional de um $\mathrm{CD}$ deve ser criteriosa, considerando-se que um $\mathrm{CD}$ é uma estrutura de grande porte e que demanda um alto investimento.

O presente artigo está organizado em seis seções. Além desta seção introdutória, tem-se, na seção 2, a descrição do problema. A seção 3 contempla a revisão de literatura. A seção 4 apresenta a aplicação da metodologia. A seção 5 apresenta o estudo de campo da empresa do ramo alimentício analisada. Os resultados obtidos são apresentados na seção 6 e, finalmente, a seção 7 apresenta as considerações finais da presente pesquisa.

\section{Descrição do problema}

A visão da empresa é dedicada a ser o principal fornecedor de serviços de logística para cadeias de restaurantes em todo o mundo, por meio da criação de um ambiente de trabalho excelente para seus funcionários e da entrega de valor inigualável para seus clientes. Para levar os produtos da rede a diversos lugares, a rede FASTFOOD conta com os serviços de uma empresa de operação logística e multinacional de capital 100\% americano.

Existem vários estudos voltados a soluções dos problemas de distribuição, dentre eles destacam-se os estudos de estruturação em CDs, que apresentam diversas técnicas eficazes de solução que servem para o sistema de distribuição.

Por esse motivo, torna-se essencial a utilização de um processo que aborde dados reais e realize a análise abrangente e concreta das informações para a tomada de decisão da estruturação de um CD. Tendo em vista demonstrar a eficácia da metodologia teórica de apoio à tomada de decisão para definição estrutural e operacional de CD no setor alimentício desenvolvida neste estudo, foi proposta a elaboração de um estudo de campo para a aplicação do processo.

O presente estudo aborda um processo para a estruturação de um CD que envolve processo de decisão com múltiplos critérios e o processo AHP, demonstrando sua aplicabilidade na escolha da melhor alternativa. Para a obtenção das alternativas, foram realizados questionários, em conformidade com o processo AHP. O processo aqui apresentado poderá servir de base para os pesquisadores que atuam em CDs das mais diversas áreas.

\section{Revisão da literatura}

Segundo Rao (2007), a Tomada de Decisões com Múltiplos Critérios (Multiple Criterion Decision Making, MCDM) se refere a tomadas de decisões na presença de critérios conflitantes, ou seja, a melhora de um determinado critério pode fazer com que haja a piora em outro(s) critério(s). Encontrar uma solução que atenda adequadamente aos diversos critérios apresentados por um determinado problema é, em geral, bastante complexa. Os problemas MCDM 
podem ser classificados em duas categorias: Tomada de Decisão com Múltiplos Atributos (Multiple Attribute Decision Making, MADM) e Tomada de Decisão com Múltiplos Objetivos (Multiple Objective Decision Making, MODM) dependendo, como o próprio nome diz, de o problema possuir múltiplos atributos (informações), que é caso do presente trabalho, ou se possui múltiplos objetivos, respectivamente.

Para solucionar problemas do tipo MADM, os métodos são categorizados pelo tipo de informação recebida dos decisores, que pode seguir um mesmo nível de importância para os atributos ou, então, a importância entre os atributos pode ser diferente, o que remete aos métodos das escolas americanas e francesas.

Os métodos da Escola Americana estão associados à Teoria da Utilidade Multiatributo, que, por sua vez, se baseia na hipótese de que, em qualquer problema de decisão, existe uma função de valor real sobre o conjunto de alternativas, função esta que agrega os atributos e que deve ser definida pelo decisor. Assim, esta teoria assume que o decisor é capaz de identificar várias alternativas discretas para avaliação e é capaz de estruturar os critérios sobre os quais as alternativas serão avaliadas de maneira hierárquica. O processo AHP, aqui utilizado, é um dos processos mais conhecidos e talvez o mais usado no mundo e pertence à escola americana. Esse processo está baseado no conceito de análise hierárquica, que estabelece uma estruturação de critérios em níveis hierárquicos.

Outras versões têm sido construídas sobre o método clássico, buscando a superação de algumas deficiências do AHP original. Algumas destas referências, citadas em seus anos de criação, são as seguintes: (i) AHP Multiplicativo, proposto por Lootsma (1990), que introduziu modificações sobre a regra de agregação das preferências; (ii) AHP Referenciado, proposto por Watson \& Freeling (1982), que introduziu uma constante de proporcionalidade, resultado da comparação dos valores relativos dos critérios e das alternativas; (iii) AHP B-G, proposto por Belton \& Gear (1985), que utiliza o maior valor de preferência entre as alternativas (identificado após a comparação das alternativas) para a normalização das preferências em relação às demais.

Já os métodos da Escola Francesa propõem modelos mais flexíveis que não pressupõem, necessariamente, a comparação entre as alternativas e, portanto, não impõem ao decisor uma estruturação hierárquica dos critérios. Os primeiros métodos dessa escola foram os da família ELECTRE (Elinúnation Et Choix Traduisant Ia Réalité), proposto por Roy (1986), cuja principal característica está associada a um novo conceito de modelo de preferências, que pretende ser uma representação mais realista que o utilizado na Teoria da Decisão Clássica. Outra família de métodos da escola francesa, mais recente, é a do método PROMETHEE (Preference Ranking Organization Method for Enrichment Evaluations) proposta, inicialmente, por (Brans et al., 1984). Os métodos PROMETHEE usam comparações binárias entre as alternativas, avaliando os seus desempenhos critério a critério, a fim de dispor as alternativas em ordem de prioridade. Além disso, utilizam o conceito de pseudocritério, com a possibilidade de associá-lo a limites de indiferença e de preferência estrita. Dessa forma, segundo as diferenças dos desempenhos existentes entre as alternativas, o decisor poderá variar o grau de preferência (ou índice de credibilidade) de uma alternativa em relação a outra.

Em função das características do presente estudo, principalmente no que diz respeito às pessoas que foram entrevistadas (os decisores do processo), o processo AHP clássico foi o escolhido. Desta forma, pretende-se minimizar os problemas apontados por Bond et al. (2008), no que diz respeito aos decisores definirem os critérios e hierarquizá-los em seus processos de decisão. Isto porque, como já explicitado, o AHP estrutura os critérios em níveis hierárquicos, facilitando a compreensão dos decisores.

O processo AHP pode avaliar métricas de natureza qualitativa. No entanto, na quantificação dos relacionamentos causais por meio da escala de comparação pareada (escala Saaty), o processo agrupa partes de uma situação complexa, segundo propriedades comuns; identifica os fatores influentes e mede o peso de sua influência, comparando-os aos pares e traduzindo as importâncias relativas em uma escala (Agarwal et al., 2006).

Muitos autores têm desenvolvido suas pesquisas utilizando o processo AHP na resolução de problemas de tomada de decisão nas mais diversas áreas. Em todos eles, o processo AHP tem como intuito auxiliar os tomadores de decisões de forma a garantir melhor organização, documentação, compartilhando o entendimento sobre os diversos questionamentos da empresa. Alguns destes trabalhos estão relacionados a seguir.

Onut et al. (2008) apontaram um processo de análise para minimizar o tempo de descolamento do produto dentro de uma empresa, pela otimização do layout de seu CD. Para o desenvolvimento da pesquisa, foi utilizado o processo AHP para classificar os produtos, usando critérios e subcritérios definidos pela administração da empresa. Muralidharan et al. (2002) propuseram um modelo de cinco etapas do AHP para auxiliar os tomadores de decisão na classificação e seleção dos fornecedores com relação a nove critérios de avaliação, dentre os quais qualidade, entrega, flexibilidade. Pessoas de diferentes funções da empresa foram envolvidas no processo de seleção. Chan et al. (2006) propuseram um AHP, envolvendo multicritérios e análise probabilística, para capturar as 
incertezas de confiabilidade de entregas. A otimização envolveu a determinação das alocações de demanda na rede, modos de transporte entre as instalações e programação da produção nas fábricas.

Vários outros autores destacam a importância da utilização do processo AHP em problemas tais como: indicadores de desempenho (Rafaeli \& Müller, 2007); localização da produção para a internacionalização da indústria alimentícia (Lorentz, 2008); CD logístico de frios (Zhi-Cheng \& Xin, 2009); sistemas elétricos de potência (Chatzimouratidis \& Pilavachi, 2009); análise sobre a localização de CD (Yi \& Dan, 2009); a escolha do local para a instalação do CD (Zhen-Zhong, 2010); seleção de alternativas para comporem o portfólio de projetos (Padovani et al., 2010); planejamento de produtos (Lee \& Hwang, 2010); engenharia nuclear (Lee \& Hwang, 2010); avaliação de investimentos (Lee et al., 2011); análise de sustentabilidade da indústria de concreto (Henry \& Kato, 2011); análise de células combustível (Hou et al., 2011); engenharia do petróleo e gás (Yang et al., 2011); índice de qualidade para energia elétrica (Passos \& Souza, 2013).

\subsection{Processo AHP}

A programação multicritério, por meio do processo AHP, é estruturada para tomada de decisão em ambientes complexos em que diversas variáveis ou critérios são considerados para a priorização e seleção de alternativas. O AHP foi desenvolvido na década de 1980 por Thomas L. Saaty e tem sido intensivamente utilizado. Atualmente é aplicado para a tomada de decisão em diversos cenários complexos em que pessoas trabalham em conjunto para tomar decisões e em que percepções humanas, julgamentos e consequências possuem repercussão de longo prazo (Bhushan \& Rai, 2004).

O processo AHP se inicia pela decomposição do problema em uma hierarquia de critérios ou atributos que são mais facilmente analisáveis e comparáveis de modo independente. A partir do momento em que essa hierarquia lógica é construída, a etapa seguinte do processo AHP é avaliar sistematicamente as alternativas por meio da comparação, duas a duas, sob a ótica de cada um dos critérios ou atributos. Essa comparação pode utilizar dados concretos das alternativas ou julgamentos humanos como forma de informação (Saaty, 2005). Segundo Cruz \& Carvalho (2003), existem algumas restrições quanto ao uso do processo AHP, dentre as quais pode-se citar a quantidade de comparações paritárias necessárias que, dependendo do problema, pode crescer muito rapidamente.

O AHP transforma as comparações, muitas vezes empíricas, em valores numéricos que são processados e comparados. O peso de cada um dos fatores permite a avaliação de cada um dos elementos dentro da hierarquia definida. Essa capacidade de conversão de dados empíricos em valores numéricos é o principal diferencial do AHP com relação a outras técnicas.

A comparação entre dois elementos, utilizando o AHP, pode ser realizada de diferentes formas (Triantaphyllou \& Mann, 1995), sendo que, no entanto, a escala de importância relativa entre duas alternativas propostas por Saaty (Saaty, 2005) é a mais amplamente utilizada. Atribuindo valores que variam de "1" a "9", a escala determina a importância relativa de uma alternativa $i$ com relação à alternativa $j$ e, reciprocamente, da alternativa $j$ em relação à alternativa $i$. As equações matemáticas do AHP não são aqui apresentadas pelo fato de serem amplamente divulgadas na literatura (Saaty, 2005).

\section{Metodologia proposta}

A metodologia é formada, basicamente, pelas seguintes quatro etapas: definição dos critérios e subcritérios; definição das alternativas e seu relacionamento com os critérios; definição da hierarquia do problema abordado; e a aplicação do processo AHP.

\subsection{Definição dos critérios e subcritérios}

Os critérios e os subcritérios têm como foco o desenvolvimento do processo para auxiliar a compreensão global do problema de acordo com as preferências dos decisores ou selecionar, dentre todas as alternativas, a solução que melhor satisfaça os objetivos dos decisores na estruturação do CD.

Para todos os critérios, foram estabelecidos subcritérios que buscam especificar a importância relativa dos critérios para a avaliação. O uso do AHP foi restrito à análise de como os critérios de desempenho rapidez; confiabilidade; qualidade; flexibilidade; e custo influenciam a seleção de um CD. Cada critério foi desmembrado em um nível inferior de subcritérios.

\subsection{Definição das alternativas e seu relacionamento com os critérios}

Com base na revisão de vários estudos e na metodologia de multicritérios, observou-se que várias são as alternativas que podem ser consideradas na estruturação de um CD. No levantamento destas possíveis alternativas, foram analisadas as listadas a seguir. Vale salientar que nesta etapa buscou-se, também, a ligação dos possíveis critérios com as possíveis alternativas, para estruturação do $\mathrm{CD}$ analisado.

- Estrutura do CD: localização do depósito; estrutura do armazém geral em termos de área; quantidade de intermediários existentes (necessários); canais de distribuição (rodoviário; 
ferroviário; marítimo; aéreo); demanda de produtos; características do produto (pesado ou leve).

- Arranjo físico ou Layout: tipo de arranjo físico (arranjo posicional ou por posição fixa, arranjo linear ou por produto, arranjo funcional ou por processo, arranjo celular ou de grupo); área de recebimento; área de separação (área de reserva, de paletes, de caixas fechadas ou fracionadas); pontos de partida de deslocamento para separador, reabastecedor; área de movimentação; tipos de equipamento de movimentação (veículos industriais: empilhadeiras; frontal, lateral, patrola; carrinhos industriais; carrinhos porta-bandeira; paleteira manual e transpaleteira elétrica; equipamentos de elevação e transporte: guindastes; guindastes auxiliares para veículos; talhas; ponte rolante e monovia; transportadores contínuos: transportadores de esteira; transportadores de rolo; transportadores de caçamba e plano inclinado); localização de entrada / saída (E/S) pontos; Projeto das docas (portas direcionadas para o transporte: $45^{\circ}$ ou $90^{\circ}$; identificar as docas de recebimento e expedição).

- Dimensionamento: espaço para armazenar os produtos de acordo com a rotatividade dos produtos (alta, média e baixa); número de prateleiras e os corredores incluindo o comprimento e a largura dos corredores; determinar estantes apropriadas (por exemplo, flow racks, drive-in (sistema de armazenagem que permite a máxima utilização do espaço disponível, tanto em superfície como em altura), porta paletes ou prateleiras); definição de uma política de alocação dos itens nas áreas de estocagem, de acordo com a família dos produtos.

- Entrada de materiais: procedimentos de chegada e descarga de veículos; procedimentos de controle de qualidade; pré-recebimento; documentação.

- Movimentação: tempo de movimentação por roteirização; quantidade de produtos; tipos de movimentação (manual, mecanizada e automática).

- Separação de pedido: tipos de separação (discreta, em batelada, em zona e em ondas, podendo haver uma combinação); emissão da lista de separação; processo de agrupamento e agendamento do pedido; sequenciamento dos pedidos da separação; sequência dos itens de separação.
- Saída de materiais: quantidade total a ser expedida (peso e volume); pontos de embarque (distância envolvida em relação aos produtos estocados e ao percurso do transporte); datas de entrega; documentação.

\subsection{Definição da forma hierárquica do problema}

O processo de tomada de decisão pode variar em empresas do mesmo segmento, devido aos diferentes perfis dos tomadores de decisão e, também, à variedade e à complexidade dos problemas decisórios. O estudo buscou mostrar a utilização do processo multicritério AHP, analisando a melhoria do processo.

Para compreender as peculiaridades da empresa, foram realizadas visitas ao $\mathrm{CD}$, cujas informações foram coletadas e aplicadas aos questionários da pesquisa para o processo de tomada de decisão multicritério. Neste contexto, realizou-se a estruturação hierárquica por meio da definição: do objetivo principal da análise; dos critérios e subcritérios que devem estar presentes no $\mathrm{CD}$ e das alternativas para a escolha do $\mathrm{CD}$.

Posterior à realização da estruturação hierárquica, faz-se necessária a seleção das prioridades dos elementos de um nível hierárquico em relação ao grau de importância para outro elemento no nível superior. Neste momento, para que os tomadores de decisão respondessem aos questionários foi apresentada a escala numérica de Saaty, para que houvesse a comparação dos fatores da hierarquia. Essa seleção foi realizada por meio da aplicação do questionário. Em seguida identificou-se o grau de importância dos critérios e subcritérios em relação ao objetivo geral dentro da estrutura hierárquica e, por meio desta pontuação, foi selecionada a alternativa que melhor atende às necessidades da empresa. Na sequência, utilizou-se o processo AHP com a teoria dos conjuntos nebulosos, em que se aplica uma função de minimização aos valores de preferência expressos pelos decisores nos diferentes juízos, obtendo-se a matriz final, conforme apresentada na seção 6 , mais adiante.

\section{Estudo de campo}

Foi realizado um estudo de campo no CD de uma empresa multinacional de grande porte do ramo alimentício de redes FASTFOOD. O período considerado para as informações de vendas foi de quatro meses, de junho a setembro de 2012. A empresa conta com uma equipe de 86 funcionários e atende os estados brasileiros do Paraná, Santa Catarina e Rio Grande do Sul. A quantidade de produtos distribuídos é cerca de $40 \%$ no Rio Grande do Sul; $40 \%$ no Paraná (15\% em Curitiba e região metropolitana e $25 \%$ no norte); e 20\% em Santa Catarina. 
O processo de venda funciona por meio do sistema JDEDWARDS, ou seja, os pedidos das lojas são feitos na hora e dia marcados. Depois do fechamento dos pedidos, ocorre o processo de análise de estoque para verificar se todos os produtos colocados no pedido têm como serem atendidos. Desta maneira, o CD classifica as frequências e a rota de entrega, por meio de um roteirizador. A roteirização é definida pela quantidade de vendas e, por meio destas, definem-se quais os veículos que devem ser utilizados para transportar os pedidos para as lojas. Já a programação de separação da mercadoria é realizada de acordo com as rotas que, por sua vez, ocorrem de acordo com as frequências, conforme ilustrado na Figura 1.

Ao finalizar o processo de análise da distribuição, é realizado o faturamento que, por sua vez, depende dos estágios (congelado, resfriado e seco) e, em seguida, são gerados relatórios de separação para cada estágio, conforme mostrado na Figura 2.

$\mathrm{Na}$ área de congelados, o sistema de armazenagem é composto por drive-in e porta-palete, sendo que possui disponibilidade de 1143 paletes e a temperatura ambiente é de $-25^{\circ} \mathrm{C}$. Na área de resfriados, o sistema de armazenagem é composto por drive-in, cujos produtos são dispostos da mesma maneira que os congelados, e a temperatura é de $1^{\circ} \mathrm{C}$ a $4^{\circ} \mathrm{C}$ com disposição para 512 paletes. $\mathrm{Na}$ área de secos, existem nove ruas, de A a I. Na rua A, o sistema é composto por drive-in para 2 paletes; no restante do armazém, trabalha-se com porta-palete, sendo que há disponibilidade de 2122 paletes.

O sistema de separação de pedido é em linha e todo o processo é manual (operadores "montam" os

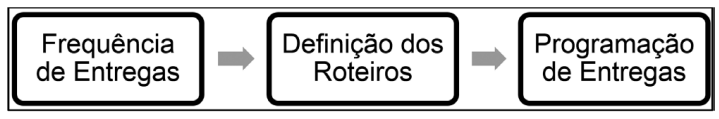

Figura 1. Sequenciamento das Operações na empresa analisada.

\begin{tabular}{|ccc|}
\hline $\begin{array}{c}\text { Processo de } \\
\text { análise de estoque }\end{array}$ & $\begin{array}{c}\text { Separação dos estágios } \\
\text { (Congelado, Refriado e Seco) }\end{array}$ \\
\hline \begin{tabular}{ccc}
\hline \\
0
\end{tabular} & 0 & 0 \\
\hline & Faturamento & \\
\hline
\end{tabular}

Figura 2. Continuação do Sequenciamento das Operações na empresa analisada. paletes conforme a documentação). Em seguida ao processo de separação de cada estágio seco, resfriado e congelado, os paletes são armazenados para expedição. Os paletes dos produtos congelados, resfriados ficam em seus setores respectivos e os paletes do setor seco são colocados dentro da antecâmara para serem carregados. A temperatura da antecâmara varia de $2^{\circ} \mathrm{C}$ a $7^{\circ} \mathrm{C}$ na frente das portas dos setores de congelados e resfriados, para que os paletes destes setores, no processo de movimentação para o transporte externo, não sofram choque térmico.

$\mathrm{O}$ processo de expedição inicia-se com o carregamento dos congelados, que ficam na parte da frente do veículo, conforme o volume do produto e classificação das lojas (identificação dos clientes que estão carregando e o lado em que cada cliente receberá o produto, pela porta direita ou esquerda). Ao finalizar toda a separação que ocorreu durante o dia, é efetuada a contagem de estoque para verificar a quantidade de produtos e se o processo de separação ocorreu da maneira planejada. Na Figura 3 a seguir, tem-se a estrutura do processo geral do $\mathrm{CD}$ analisado.

\section{Obtenção dos resultados}

Para a definição estrutural e operacional do $\mathrm{CD}$ aqui analisado, três alternativas (A, B e C) foram analisadas sob a perspectiva dos mesmos cinco critérios (rapidez; confiabilidade; qualidade; flexibilidade; e custo).

\subsection{Definição dos critérios e subcritérios para o cd analisado}

Tomando por base os estudos de Onut et al. (2008), Christopher (2011), Dornier et al. (2011); e, também, a Figura 4 a seguir, têm-se os critérios/atributos que poderão ser utilizados para "alimentar" o processo de análise de decisão a fim de melhorar o processo de escolha de um CD. Como já mencionado, os atributos considerados são: rapidez; confiabilidade; qualidade; flexibilidade; e custo.

Já com base na revisão dos estudos de Muralidharan et al. (2002), Onut et al. (2008), Dornier et al. (2011); e, também, a Figura 5 a seguir, têm-se possíveis subcritérios, enquadrados em cada um dos critérios apresentados na Figura 4, para melhorar o processo de escolha.

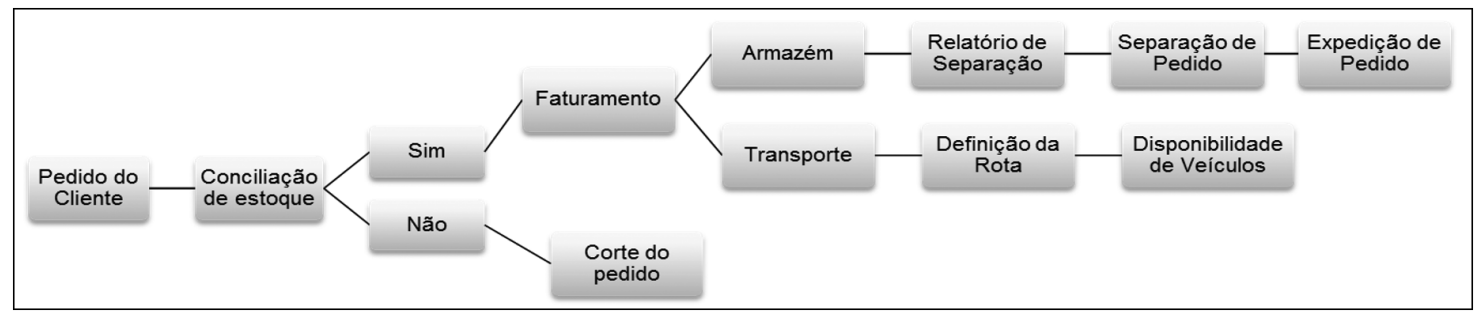

Figura 3. Estrutura do Processo. 


\subsection{Definição das alternativas e seu relacionamento com os critérios para o CD analisado}

Nesta etapa, buscou-se identificar possíveis alternativas necessárias para análise de decisão que possam ser utilizadas para implantação de um CD do ramo alimentício. A Tabela 1, a seguir, mostra as informações referentes à somatória de cada grupo de produtos (congelado; resfriado; seco) de Stock Keeping Unit $\left(\mathrm{Sku}_{\mathrm{s}}\right)$ a cada um dos clientes (1, 2 e 3), além da demanda prevista; quantidade de produtos por palete; quantidade de posição atual (quantidade de paletes que existem no congelado, resfriado e seco); área total para cada tipo de produto; e, finalmente, a quantidade de posições necessárias (quantidade de paletes necessária para o congelado, resfriado e seco).

Quanto ao armazém, foram propostos três modelos que apresentam padronização entre seus corredores e espaços de armazenagem, podendo apresentar formatos quadrados e retangulares. As dimensões dos espaços de armazenagem foram definidas, considerando a soma da capacidade volumétrica. A Tabela 2, a seguir, mostra as informações referentes às alternativas. A primeira alternativa foi determinada para sanar a necessidade da empresa de permanecer

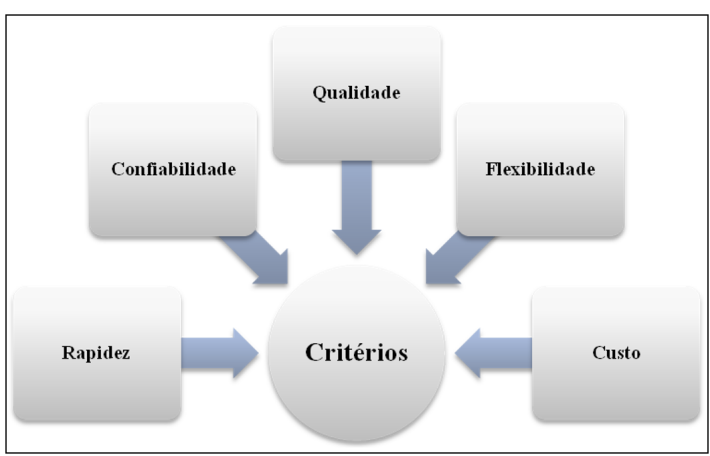

Figura 4. Estruturação dos critérios. com o mesmo sistema de informações já existente na empresa; a segunda e terceira alternativas foram definidas para que o $\mathrm{CD}$ tenha maior flexibilidade no sistema de informações, as áreas do armazém tenham um aumento de $30 \%$ e a quantidade de posições, por sua vez, tenham um aumento $20 \%$. A seguir será detalhada cada uma destas alternativas (A, B e C), para a escolha do CD.

\subsubsection{Descrição das alternativas}

Nesta seção, buscou-se o agrupamento dos dados coletados e a definição das alternativas junto aos tomadores de decisão (o gerente e os supervisores).

Desta forma, ficou definido que o processo funcionará da seguinte forma para as três alternativas apresentadas mais adiante: cada um dos produtos será identificado como leve ou pesado; os produtos de maior volume e quantidade de giro serão armazenados em drive-in e os de menor volume e baixo giro, em porta-paletes; o sistema de separação será em linha por batelada; o processo de separação iniciará do mais pesado para o mais leve, porque os pesados formam a base dos paletes e cada operador separará uma área. Para manter a temperatura do congelado e resfriado serão utilizados amônia e freon (sistema a gás) e os paletes vazios ficarão em porta-paletes na parte de cima das docas com 5 níveis. Já o armazém deverá ficar estruturado conforme a Tabela 2 anterior, sendo que os diferenciais para cada uma das três alternativas estão descritos a seguir.

Alternativa A: A localização da empresa será na região industrial, de sua própria propriedade, o layout será baseado no princípio de fluxo e o transporte rodoviário e a empresa terão sua própria frota. A área de resfriados o sistema de armazenagem usado será por drive-in de 2 e 3 e com tem 1 porta automática do tipo Hite-rite (portas para docas com diversos

\begin{tabular}{|c|c|c|c|c|}
\hline Rapidez & Confiabilidade & Qualidade & Flexibilidade & Custo \\
\hline $\begin{array}{l}\text { - Processamento das } \\
\text { informações } \\
\text { - Recebimento } \\
\text { - Armazenagem } \\
\text { - Movimentação } \\
\text { - Transferência } \\
\text { - Saída }\end{array}$ & $\begin{array}{l}\text { - Prazo de entrega } \\
\text { - Produto entregue } \\
\text { sem avaria } \\
\text { - Pedido atendido } \\
\text { com precisão no } \\
\text { faturamento e } \\
\text { documentação }\end{array}$ & $\begin{array}{l}\text { - Atendimento dos } \\
\text { pedidos } \\
\text { - Tempo de resposta } \\
\text { ao cliente } \\
\text { - Conferência do } \\
\text { produto } \\
\text { - Proteção do } \\
\text { produto estoca do } \\
\text { - Embalagem } \\
\text { - Temperatura } \\
\text { conforme a } \\
\text { especificação } \\
\text { - Montagem do } \\
\text { palete }\end{array}$ & $\begin{array}{l}\text { - Produto/Serviço } \\
\text { - Quantidade } \\
\text { - Volume } \\
\text { - Variedade } \\
\text { - Disposição dos } \\
\text { produtos } \\
\text { - Entrega }\end{array}$ & $\begin{array}{l}\text { - Espaço físico } \\
\text { - Transporte } \\
\text { - Localização } \\
\text { geográfica } \\
\text { - Niveis de estoque } \\
\text { - Manutenção de } \\
\text { inventário } \\
\text { - Mão de obra } \\
\text { - Preço do produto } \\
\text { - Previsão de } \\
\text { demanda } \\
\text { - Sistema de } \\
\text { informações } \\
\text { (software) } \\
\text { - Equipamentos }\end{array}$ \\
\hline
\end{tabular}

Figura 5. Estruturação dos subcritérios. 
Tabela 1. Histórico da Empresa.

\begin{tabular}{|c|c|c|c|c|c|c|}
\hline $\begin{array}{c}\text { DESCRIÇÃO } \\
\text { DO SETOR }\end{array}$ & $\begin{array}{l}\text { QUANTIDADE } \\
\text { DE SKU }\end{array}$ & $\begin{array}{l}\text { DEMANDA } \\
\text { PREVISTA } \\
\text { (unid./mês) }\end{array}$ & $\begin{array}{c}\text { QUANTIDADE DE } \\
\text { PRODUTO } \\
\text { (unid./palete) }\end{array}$ & $\begin{array}{c}\text { QUANTIDADE } \\
\text { DE POSIÇÃO } \\
\text { ATUAL }\end{array}$ & $\begin{array}{c}\text { ÁREA } \\
\text { TOTAL - } \\
\text { ATUAL } \\
\left(\mathbf{m}^{2}\right)\end{array}$ & $\begin{array}{l}\text { QUANTIDADE } \\
\text { DE POSIÇÃO } \\
\text { NECESSÁRIA }\end{array}$ \\
\hline $\begin{array}{l}\text { Congelado - } \\
\text { Cliente } 1\end{array}$ & 77 & 31,536 & 4,597 & 642 & \multirow{3}{*}{1,098} & 721 \\
\hline $\begin{array}{l}\text { Congelado - } \\
\text { Cliente } 2\end{array}$ & 31 & 11,762 & 1,549 & 243 & & 274 \\
\hline $\begin{array}{l}\text { Congelado - } \\
\text { Cliente } 3\end{array}$ & 26 & 20,137 & 2,329 & 258 & & 270 \\
\hline $\begin{array}{l}\text { Resfriado - } \\
\text { Cliente } 1\end{array}$ & 39 & 14,465 & 2,474 & 353 & \multirow{3}{*}{414} & 369 \\
\hline $\begin{array}{l}\text { Resfriado - } \\
\text { Cliente } 2\end{array}$ & 11 & 8,433 & 952 & 114 & & 120 \\
\hline $\begin{array}{l}\text { Resfriado - } \\
\text { Cliente } 3\end{array}$ & 9 & 5,713 & 1,800 & 45 & & 47 \\
\hline $\begin{array}{l}\text { Seco - } \\
\text { Cliente } 1\end{array}$ & 337 & 51,835 & 54,834 & 1,290 & \multirow{3}{*}{2,505} & 1,442 \\
\hline $\begin{array}{l}\text { Seco - } \\
\text { Cliente } 2\end{array}$ & 335 & 26,093 & 9,563 & 530 & & 644 \\
\hline $\begin{array}{l}\text { Seco - } \\
\text { Cliente } 3\end{array}$ & 80 & 19,534 & 10,938 & 302 & & 367 \\
\hline TOTAL & 945 & 189,508 & 89,036 & 3,777 & 4,017 & 4,254 \\
\hline
\end{tabular}

Tabela 2. Cálculos das alternativas.

\begin{tabular}{|c|c|c|c|c|c|c|}
\hline $\begin{array}{l}\text { DESCRIÇÃO } \\
\text { DO SETOR }\end{array}$ & $\begin{array}{l}\text { QUANTIDADE } \\
\text { DE SKU }\end{array}$ & $\begin{array}{l}\text { QUANTIDADE } \\
\text { DE POSIÇÃO }\end{array}$ & $\begin{array}{l}\text { QUANTIDADE } \\
\text { DE DOCA }\end{array}$ & $\begin{array}{c}\text { ÁREA } \\
\text { SETOR } \\
\left(\mathbf{m}^{2}\right)\end{array}$ & $\begin{array}{c}\text { ÁREA } \\
\text { ANTECÂMERA } \\
\left(\mathbf{m}^{2}\right)\end{array}$ & $\begin{array}{l}\text { ÁREA TOTAL } \\
\left(\mathbf{m}^{2}\right)\end{array}$ \\
\hline $\begin{array}{l}\text { Alternativa } 1 \\
\text { Congelado }\end{array}$ & 134 & 1,265 & \multirow{3}{*}{17} & 1,215 & \multirow{2}{*}{407} & \multirow{3}{*}{5,725} \\
\hline $\begin{array}{l}\text { Alternativa } 1 \\
\text { Resfriado }\end{array}$ & 54 & 536 & & 426 & & \\
\hline $\begin{array}{l}\text { Alternativa } 1 \\
\text { Seco }\end{array}$ & 752 & 2,453 & & 2,896 & 704 & \\
\hline $\begin{array}{l}\text { Alternativa } 2 \\
\text { Congelado }\end{array}$ & 134 & 1,518 & \multirow{3}{*}{17} & 1,580 & 519 & \multirow{3}{*}{7,341} \\
\hline $\begin{array}{l}\text { Alternativa } 2 \\
\text { Resfriado }\end{array}$ & 59 & 643 & & 555 & 519 & \\
\hline $\begin{array}{l}\text { Alternativa } 2 \\
\text { Seco }\end{array}$ & 752 & 2,944 & & 3,770 & 917 & \\
\hline $\begin{array}{l}\text { Alternativa } 3 \\
\text { Congelado }\end{array}$ & 134 & 1,536 & \multirow{3}{*}{$31(17-14)$} & 1,580 & & \multirow{3}{*}{7,341} \\
\hline $\begin{array}{l}\text { Alternativa } 3 \\
\text { Resfriado }\end{array}$ & 59 & 660 & & 555 & $230-289$ & \\
\hline $\begin{array}{l}\text { Alternativa } 3 \\
\text { Seco }\end{array}$ & 752 & 2,996 & & 3,770 & $407-510$ & \\
\hline
\end{tabular}

meios de instalação, podendo ser utilizadas em áreas secas e frigoríficas) para flexibilidade da operação e sem perda de temperatura. Para a área de congelados, o sistema de armazenagem será por drive-in de 2 e porta-paletes, 3 portas automáticas Hite-rite e com antecâmara na frente do congelado com fácil acesso ao resfriado. A área de secos terão nove ruas de A a I, com corredores de movimentação de $6,41 \mathrm{~m}$, sistema drive-in de 3 e porta-paletes, 1 porta automática Hite-rite e 3 portas de emergência.

Alternativa B: A localização será na região industrial, alugada por um investidor para a empresa, o layout será baseado no princípio de fluxo, o transporte rodoviário, tendo sua 
própria frota. $\mathrm{Na}$ área de congelados, o sistema de armazenagem será por drive-in de $2,4 \mathrm{e}$ porta-paletes, 4 portas automáticas Hite-rite e com antecâmara na frente do congelado com fácil acesso ao resfriado. Na área de resfriados, o sistema de armazenagem usado será por drive-in de 3 e 1 porta automática Hite-rite para flexibilidade da operação e sem perda de temperatura. A área de secos terá 11 ruas A a L, por sistema drive-in de 2, 3 e porta-paletes, com corredores de movimentação de $7,18 \mathrm{~m}, 1$ porta automática e 3 portas de emergência. O CD funcionará com a inclusão de um sistema de gerenciamento de armazém (WMS; Warehouse Management System, ou seja, Sistema de Gerenciamento de Armazém) com códigos de barras para controle de mercadorias e endereços, até a complexidade de toda a operação das atividades diárias de um armazém. Esse sistema controlará as operações básicas do processo de armazenagem como: recebimento, estocagem, carregamento, separação e expedição de forma otimizada, com a finalidade de maximizar os recursos da empresa. Cada operador separará uma área. O recebimento de mercadorias no CD iniciará quando o caminhão dos fornecedores chegarem à portaria. A portaria deverá realizar a verificação dos documentos apresentados com os pedidos solicitados pelo departamento de suprimentos. Os dados constantes nos documentos serão digitados, a fim de dar início ao recebimento das mercadorias, caso não haja divergência. Os documentos pertinentes à mercadoria ficarão na portaria para posterior envio ao recebimento físico. No recebimento, os produtos serão conferidos e o operador, por meio do coletor de dados, lançará no sistema WMS a quantidade de produto contada e irá gerar uma etiqueta com a quantidade do produto que será colocado no setor de liberação (faixa amarela) para ser estocado. Caso haja algum erro, o lote de entrada será bloqueado, devendo ser verificado o ocorrido. Depois da conferência dos produtos no recebimento, os produtos serão retirados e colocados no local de espera para armazenagem. Os paletes serão estocados conforme a disponibilidade de endereços, por meio de um simples controle de localidade. Na separação, o sistema, emitirá uma lista com o número do pedido e informará a quantidade a ser separada e em qual endereço e unidade de armazenamento a mercadoria deverá ser retirada. No caso de ir para um endereço errado, o sistema não lê a etiqueta da unidade, informa que está errado e que é preciso pegar a correta, dando mais acurácia ao estoque e um controle muito maior do estoque. Depois da separação, os produtos ficarão na área de consolidação dos pedidos. Na expedição, as cargas separadas serão conferidas por etiquetas visuais com a sigla do cliente e carregadas. Caso ainda haja alguma divergência, estas serão solucionadas por meio do WMS que mantém controle e gerencia todas as atividades do CD.

Alternativa C: A localização será na região industrial, alugada por um investidor para a empresa, layout baseado no princípio de fluxo, transporte rodoviário, tendo sua própria frota. A área de congelados, o sistema de armazenagem será por drive-in de 3,4 e porta-palete, 8 portas automáticas Hite-rite e com antecâmara na frente do congelado com fácil acesso ao resfriado. $\mathrm{Na}$ área de resfriados, o sistema de armazenagem usado será por drive-in de 3, 2 porta automática Hite-rite para flexibilidade da operação e sem perda de temperatura. A área de secos terá 11 ruas, de $\mathrm{A}$ a $\mathrm{L}$, com sistema drive-in de 2,3 e porta-paletes, com corredores de movimentação de $6,91 \mathrm{~m}, 2$ portas automáticas e 3 portas de emergência. O CD funcionará com a inclusão do WMS da mesma maneira que foi sugerido para a alternativa B. O produto que chegar pelo fornecedor não será armazenado e deverá ser recebido em uma extremidade da instalação de onde será expedido do outro lado. Este setor é conhecido como crossdocking.

\subsubsection{Análise das alternativas}

A análise das alternativas é realizada por meio da aplicação de questionário, no qual se busca, junto aos decisores, identificar a importância dos critérios e subcritérios em relação às alternativas recomendadas. Desta maneira, todas as alternativas são confrontadas com os critérios estabelecidos na hierarquia, sendo considerados os diferentes níveis de impacto dos critérios em relação às alternativas. Nesse processo, é empregada a análise dos critérios e subcritérios em relação às alternativas para a priorização final, identificando deste modo a melhor alternativa para a definição estrutural e operacional de CD.

Assim, essa é uma etapa decisiva do processo de tomada de decisão, em que são abordadas as experiências e conhecimentos técnicos dos tomadores de decisão, fornecendo maior consistência ao método proposto. A minimização dos custos é essencial para a organização obter maiores lucros. Deve-se visar o aumento da produtividade a custos baixos. A empresa busca a satisfação plena dos clientes por meio da 
realização de seus serviços com total qualidade, o que implica entregar os produtos em conformidade com as especificações referentes às características específicas de cada produto, até mesmo a fragilidade. Quanto à flexibilidade, a empresa busca ser capaz de atender a todas as mudanças determinadas pelos seus clientes. O critério rapidez é importante devido à realização de serviços de transportes da empresa ser em diversas localidades do Brasil e, por este motivo, faz-se necessário utilizar uma modalidade de transporte que dê condições para atender às inúmeras lojas distribuídas entre pequenas e grandes cidades. Quanto à confiabilidade, o peso se reflete na confiança da entrega do produto, atendendo satisfatoriamente o cliente e no tempo certo.

Em relação às alternativas, todas têm os requisitos desejáveis à empresa, pois conseguem atender à necessidade principal estabelecida pelos critérios e subcritérios. No entanto, o que as difere é que alguns decisores acreditam que para reduzir alguns dos problemas operacionais é necessário adquirir sistemas de informações ágeis, evitando erros tanto na emissão, como no recebimento de pedidos. A empresa deve desenvolver formulários eletrônicos para envio e recepção dos pedidos via internet e adquirir um sistema de gerenciamento de armazém com módulos de previsão de vendas, recebimento de pedidos, controle de estoques próprios e dos fornecedores, relatório de vendas por loja e acompanhamento diário dos indicadores de desempenho.

\subsection{Definição da forma hierárquica do problema}

O processo multicritério AHP procura fazer com que todo o procedimento da empresa seja o mais objetivo e transparente possível. Portanto as soluções dos problemas passam a envolver aspectos que devam representar da melhor forma possível, as preferências do tomador de decisão. A aplicação do processo ocorreu por meio dos seguintes passos.

$1^{\circ}$ Passo: Para a formulação do processo faz-se necessário apresentar a estrutura hierárquica deste estudo de campo, conforme a Figura 6, a seguir.

$2^{\circ}$ Passo: Na sequência, faz-se necessário que gerentes e supervisores do $\mathrm{CD}$ realizem comparações entre os pares de critérios, a fim de determinar a intensidade da importância relativa de um critério sobre o outro e verificar a aplicabilidade das variáveis que os compõem, conforme Tabela 3.

Essa fase identifica o grau de importância dos critérios em relação ao objetivo geral dentro da estrutura hierárquica. Da mesma maneira, foram realizadas as comparações paritárias para todos os subcritérios dos critérios rapidez, confiabilidade, qualidade, flexibilidade e custo, explicitados nas Figuras 5 e 6 . A análise das alternativas é realizada por meio da aplicação das comparações entre os

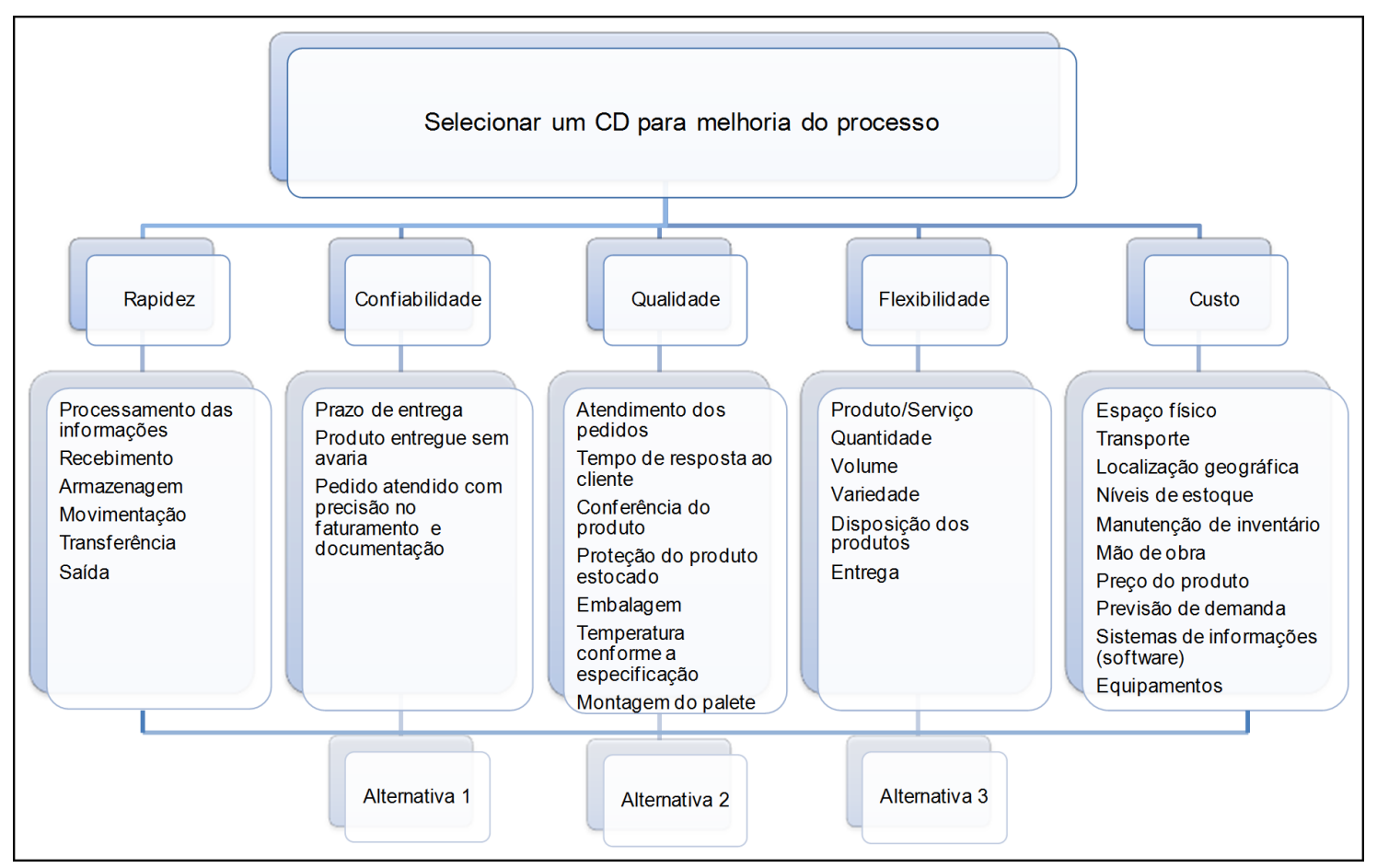

Figura 6. Estrutura Hierárquica do Processo de estudo de campo. 
pares, em que busca, junto aos decisores, identificar a relevância dos critérios e subcritérios em relação às alternativas propostas.

Para isso foi aplicado o questionário a três decisores da empresa. O questionário permitiu identificar a relevância dos critérios e subcritérios em relação à descrição do problema e a definição estrutural e operacional de CDs. Nessa análise, é provável que apareçam inconsistências, que são toleráveis ao limite de 0,10 .

\subsection{Aplicação do processo AHP}

Nesta seção, faz-se a aplicação do processo AHP por meio de suas equações matemáticas.

$1^{\circ}$. Passo: Para a atribuição dos valores de intensidade de importância na determinação da estrutura do $\mathrm{CD}$, foram geradas matrizes de comparação paritária e os respectivos vetores de prioridade relativa para cada um dos critérios, subcritérios e alternativas. Os valores obtidos, já normalizados, são apresentados nas Tabelas 4 a 6 a seguir.

Na última coluna desta Tabela 4, têm-se, em ordem de prioridade decrescente, os critérios: custo $(0,364)$; qualidade $(0,222)$; flexibilidade $(0,167)$; rapidez $(0,129)$; e confiabilidade $(0,119)$. Portanto, o "custo" é o critério considerado mais importante e a "confiabilidade", o menos importante.

Da mesma forma, na última coluna desta Tabela 5, têm-se, a seguinte ordem de prioridade dos subcritérios segundo o critério rapidez: 0,311 para o recebimento;
0,202 para a saída; 0,180 para a movimentação; 0,139 para a armazenagem; 0,086 para a transferência; e 0,082 para o processamento de informações. Portanto o "recebimento" tem prioridade sobre os outros subcritérios para o critério rapidez.

De forma análoga, obteve-se a seguinte ordem de prioridade dos subcritérios segundo o critério confiabilidade: 0,450 para o pedido atendido com precisão no faturamento e documentação; 0,323 para o prazo de entrega; e 0,228 para o produto entregue sem avaria. Portanto o "pedido atendido com precisão no faturamento e documentação" tem prioridade sobre os outros subcritérios para o critério confiabilidade. Já a ordem de prioridade dos subcritérios segundo o critério qualidade: 0,245 para o tempo de resposta ao cliente; 0,206 para o atendimento do pedido; 0,204 para a temperatura conforme a especificação; 0,104 para a proteção do produto estocado; 0,093 para a conferência do produto; 0,075 para a embalagem; e 0,072 para a montagem de palete. Portanto o "tempo de resposta ao cliente" tem prioridade sobre os outros subcritérios para o critério confiabilidade.

Tem-se, ainda, a ordem de prioridade dos subcritérios, segundo o critério flexibilidade: 0,303 para a disposição dos produtos; 0,216 para o produto/serviço; 0,126 para a quantidade; 0,153 para a variedade; 0,118 para o volume; e 0,083 para a entrega. E, finalmente, a ordem de prioridade dos subcritérios segundo o critério custo: 0,201 para o sistema de informações (software); 0,108 para a mão de obra; 0,103 para os equipamentos; 0,100 para o preço do produto; 0,098 para a manutenção de inventários; 0,088 para os níveis de estoque; 0,087 para a previsão de demanda;

Tabela 3. Matriz de Comparação Paritária entre os Critérios.

\begin{tabular}{lccccc}
\hline \multicolumn{7}{c}{ Matrizes de Comparação Paritária entre os Critérios } \\
\hline Critérios & Rapidez & Confiabilidade & Qualidade & Flexibilidade & Custo \\
\hline Confiabilidade & $\mathbf{1}$ & 0,200 & 0,333 & 1 & 0,143 \\
Qualidade & 0,200 & $\mathbf{1}$ & 0,200 & 1 & 0,200 \\
Flexibilidade & 3 & 1 & $\mathbf{1}$ & 0,200 & 0,333 \\
Custo & 1 & 1 & 0,333 & $\mathbf{1}$ & 0,333 \\
\hline
\end{tabular}

Tabela 4. Matriz Normalizada e Vetor de Prioridade Relativa dos Critérios.

\begin{tabular}{|c|c|c|c|c|c|c|}
\hline \multicolumn{7}{|c|}{ Matriz Normalizada e Vetor de Prioridade Relativa Wi dos Critérios } \\
\hline Critérios & Rapidez & Confiabilidade & Qualidade & Flexibilidade & Custo & $\begin{array}{c}\text { Vetor de } \\
\text { Prioridade } \\
\text { Relativa }\end{array}$ \\
\hline Rapidez & 0,185 & 0,024 & 0,068 & 0,294 & 0,071 & 0,129 \\
\hline Confiabilidade & 0,037 & 0,122 & 0,041 & 0,294 & 0,100 & 0,119 \\
\hline Qualidade & 0,556 & 0,122 & 0,206 & 0,059 & 0,166 & 0,222 \\
\hline Flexibilidade & 0,185 & 0,122 & 0,068 & 0,294 & 0,166 & 0,167 \\
\hline Custo & 0,037 & 0,610 & 0,617 & 0,059 & 0,498 & 0,364 \\
\hline $\begin{array}{l}\text { Soma da } \\
\text { Coluna }\end{array}$ & 1 & 1 & 1 & 1 & 1 & 1 \\
\hline
\end{tabular}


0,082 para a localização geográfica; 0,060 para o transporte; e 0,050 para o espaço físico.

Para as alternativas, a ordem de prioridade obtida foi a seguinte: 0,743 para a alternativa $C ; 0,182$ para a alternativa $\mathrm{B} ; \mathrm{e} 0,075$ para a alternativa $\mathrm{A}$, Portanto a alternativa $\mathrm{C}$ tem prioridade sobre as demais. Estes valores encontram-se na Tabela 6.

$2^{\circ}$ Passo: Os valores normalizados das alternativas e seus vetores de prioridade relativa estão na Tabela 6 , nos quais os componentes da hierarquia têm maior peso nos julgamentos realizados. Pode-se observar que a inclusão dos pesos dos critérios de decisão não provocou a alteração na ordem das prioridades das alternativas. Apenas a título de exemplificação, são apresentados na Tabela 7, última coluna, os autovetores para os critérios, mostrando que o "custo", com valor de 1,681, continua sendo o de maior importância.
Na Tabela 8, última coluna, estão os autovetores para cada alternativa: 2,394 para a alternativa $\mathrm{C}$; 0,491 para a alternativa B; e 0,194 para a alternativa A. Portanto a alternativa $\mathrm{C}$ continua sendo a de maior importância.

$3^{\circ}$ Passo: Para a atribuição dos autovetores, autovalores e índices de consistência (IC) na determinação da estrutura $\mathrm{CD}$, foram elaboradas as Tabelas 9 a 11, a seguir, que mostram tais valores para cada um dos critérios, subcritérios e alternativas.

Vale lembrar que os autovetores e os vetores de prioridade relativa determinam a medida de consistência de uma matriz. A Tabela 10 mostra os valores de $\lambda_{\text {máx }}$ dos critérios, subcritérios e alternativas. Os valores de $\lambda_{\text {máx }}$ relacionam os critérios da matriz de consistência e a quantidade $n$, seja de critérios e de subcritérios de cada critério.

Tabela 5. Matriz Normalizada e Vetor de Prioridade Relativa dos Subcritérios do Critério Rapidez.

\begin{tabular}{lccccccc}
\hline \multicolumn{7}{c}{ Matriz Normalizada e Vetor de Prioridade Relativa Wi dos Subcritérios do Critério Rapidez } \\
\hline \multicolumn{1}{c}{$\begin{array}{c}\text { Processamento } \\
\text { das }\end{array}$} & Recebimento & Armazenagem & Movimentação & Transferência & $\begin{array}{c}\text { Vetor de } \\
\text { Saída }\end{array}$ & $\begin{array}{c}\text { Trioridade } \\
\text { Relativa }\end{array}$ \\
\hline $\begin{array}{l}\text { Processamento } \\
\text { das informaçãos }\end{array}$ & $\mathbf{0 , 1 6 7}$ & 0,070 & 0,039 & 0,032 & 0,098 & 0,086 & $\mathbf{0 , 0 8 2}$ \\
Recebimento & 0,167 & $\mathbf{0 , 3 4 8}$ & 0,586 & 0,223 & 0,490 & 0,052 & $\mathbf{0 , 3 1 1}$ \\
Armazenagem & 0,167 & 0,050 & $\mathbf{0 , 1 1 7}$ & 0,223 & 0,020 & 0,259 & $\mathbf{0 , 1 3 9}$ \\
Movimentação & 0,167 & 0,116 & 0,117 & $\mathbf{0 , 2 2 3}$ & 0,196 & 0,259 & $\mathbf{0 , 1 8 0}$ \\
Transferência & 0,167 & 0,070 & 0,023 & 0,074 & $\mathbf{0 , 0 9 8}$ & 0,086 & $\mathbf{0 , 0 8 6}$ \\
Saída & 0,167 & 0,348 & 0,117 & 0,223 & 0,098 & $\mathbf{0 , 2 5 9}$ & $\mathbf{0 , 2 0 2}$ \\
Soma da & $\mathbf{1}$ & $\mathbf{1}$ & $\mathbf{1}$ & $\mathbf{1}$ & $\mathbf{1}$ & $\mathbf{1}$ & $\mathbf{1}$ \\
Coluna & & & & & & &
\end{tabular}

Tabela 6. Matriz Normalizada e Vetor de Prioridade Relativa das Alternativas.

\begin{tabular}{ccccc}
\hline & \multicolumn{4}{c}{ Matriz Normalizada e Vetor de Prioridade Relativa Wi das Alternativas } \\
\hline Alternativas & $\mathbf{A}$ & $\mathbf{B}$ & $\mathbf{C}$ & Vetor de Prioridade Relativa \\
\hline A & $\mathbf{0 , 1 1 1}$ & 0,024 & 0,091 & $\mathbf{0 , 0 7 5}$ \\
B & 0,333 & $\mathbf{0 , 1 2 2}$ & 0,091 & $\mathbf{0 , 1 8 2}$ \\
C & 0,556 & 0,854 & $\mathbf{0 , 8 1 8}$ & $\mathbf{0 , 7 4 3}$ \\
Soma da Coluna & $\mathbf{1}$ & $\mathbf{1}$ & $\mathbf{1}$ & $\mathbf{1}$ \\
\hline
\end{tabular}

Tabela 7. Autovetores dos Critérios.

\begin{tabular}{cccccccc}
\hline \multicolumn{7}{c}{ Cálculo do AUTOVETOR - Aw } \\
\hline Critérios & Rapidez & Confiabilidade & Qualidade & Flexibilidade & $\begin{array}{c}\text { Vetor de } \\
\text { Custo }\end{array}$ & $\begin{array}{c}\text { Prioridade } \\
\text { Relativa }\end{array}$ & Autovetor \\
\hline Rapidez & $\mathbf{1}$ & 0,200 & 0,333 & 1 & 0,143 & $\mathbf{0 , 1 2 9}$ & $\mathbf{0 , 4 4 5}$ \\
Confiabilidade & 0,200 & $\mathbf{1}$ & 0,200 & 1 & 0,200 & $\mathbf{0 , 1 1 9}$ & $\mathbf{0 , 4 2 9}$ \\
Qualidade & 3 & 1 & $\mathbf{1}$ & 0,200 & 0,333 & $\mathbf{0 , 2 2 2}$ & $\mathbf{0 , 8 8 1}$ \\
Flexibilidade & 1 & 1 & 0,333 & $\mathbf{1}$ & 0,333 & $\mathbf{0 , 1 6 7}$ & $\mathbf{0 , 6 0 9}$ \\
Custo & 0,200 & 5 & 3 & 0,200 & $\mathbf{1}$ & $\mathbf{0 , 3 6 4}$ & $\mathbf{1 , 6 8 1}$ \\
\hline
\end{tabular}


Tabela 8. Autovetores das Alternativas.

\begin{tabular}{cccccc}
\hline & \multicolumn{5}{c}{ Cálculo do AUTOVETOR - Aw } \\
\hline Alternativas & A & B & C & Vetor de Prioridade Relativa & Autovetor \\
\hline A & $\mathbf{1}$ & 0,200 & 0,111 & $\mathbf{0 , 0 7 5}$ & $\mathbf{0 , 1 9 4}$ \\
B & 3 & $\mathbf{1}$ & 0,111 & $\mathbf{0 , 1 8 2}$ & $\mathbf{0 , 4 9 1}$ \\
C & 5 & 7 & $\mathbf{1}$ & $\mathbf{0 , 7 4 3}$ & $\mathbf{2 , 3 9 4}$ \\
\hline
\end{tabular}

Tabela 9. Vetores de Consistência das Matrizes.

\begin{tabular}{|c|c|c|c|c|c|c|}
\hline \multicolumn{7}{|c|}{ Vetores de Consistência das Matrizes } \\
\hline Critérios & $\begin{array}{c}\text { Subcritérios } \\
\text { Rapidez }\end{array}$ & $\begin{array}{c}\text { Subcritérios } \\
\text { Confiabilidade }\end{array}$ & $\begin{array}{c}\text { Subcritérios } \\
\text { Qualidade }\end{array}$ & $\begin{array}{c}\text { Subcritérios } \\
\text { Flexibilidade }\end{array}$ & $\begin{array}{c}\text { Subcritérios } \\
\text { Custo }\end{array}$ & Alternativas \\
\hline 3,461 & 4,515 & 1,904 & 5,261 & 4,931 & 8,527 & 2,575 \\
\hline 3,610 & 5,598 & 1,755 & 4,801 & 4,857 & 8,316 & 2,696 \\
\hline 3,977 & 4,773 & 1,886 & 4,215 & 4,678 & 9,075 & 3,224 \\
\hline 3,648 & 4,893 & - & 3,675 & 4,835 & 8,855 & - \\
\hline 4,620 & 4,462 & - & 4,017 & 4,908 & 8,678 & - \\
\hline- & 4,952 & - & 4,219 & 5,089 & 8,713 & - \\
\hline- & - & - & 4,633 & - & 8,556 & - \\
\hline- & - & - & - & - & 8,545 & - \\
\hline- & - & - & - & - & 8,963 & - \\
\hline- & - & - & - & - & 9,376 & - \\
\hline
\end{tabular}

Tabela 10. Autovalores das Matrizes.

\begin{tabular}{ccccccc}
\hline \multicolumn{1}{c}{$\begin{array}{c}\lambda_{\max } \\
\text { Autovetor } \\
\text { Critérios }\end{array}$} & $\begin{array}{c}\text { Autovetor } \\
\text { Subcritérios } \\
\text { Rapidez }\end{array}$ & $\begin{array}{c}\text { Autovetor } \\
\text { Subcritérios } \\
\text { Confiabilidade }\end{array}$ & $\begin{array}{c}\text { Autovetor } \\
\text { Subcritérios } \\
\text { Qualidade }\end{array}$ & $\begin{array}{c}\text { Autovetor } \\
\text { Subcritérios } \\
\text { Flexibilidade }\end{array}$ & $\begin{array}{c}\text { Autovetor } \\
\text { Subcritérios } \\
\text { Custo }\end{array}$ & $\begin{array}{c}\text { Autovetor } \\
\text { Alternativas }\end{array}$ \\
\hline 3,863 & 4,865 & 1,848 & 4,403 & 4,883 & 8,760 & 2,832 \\
\hline
\end{tabular}

Tabela 11. Índices de Consistência.

\begin{tabular}{ccccccc}
\hline \multicolumn{7}{c}{ (IC) Índice de Consistência } \\
\hline Critérios & $\begin{array}{c}\text { Subcritérios } \\
\text { Rapidez }\end{array}$ & $\begin{array}{c}\text { Subcritérios } \\
\text { Confiabilidade }\end{array}$ & $\begin{array}{c}\text { Subcritérios } \\
\text { Qualidade }\end{array}$ & $\begin{array}{c}\text { Subcritérios } \\
\text { Flexibilidade }\end{array}$ & $\begin{array}{c}\text { Subcritérios } \\
\text { Custo }\end{array}$ & Alternativas \\
\hline$-0,284$ & $-0,227$ & $-0,576$ & $-0,433$ & $-0,223$ & $-0,138$ & $-0,084$ \\
\hline
\end{tabular}

A Tabela 11 mostra os IC dos critérios e subcritérios e alternativas. Os valores dos IC calculados são comparados com os valores da Razão da consistência (IR) para fornecer a Razão de Consistência (RC), apresentada na Tabela 12, mais adiante.

$4^{0}$ Passo: Para a atribuição da razão com base nas matrizes, calculou-se RC da atribuição dos níveis de intensidade de importância por meio da comparação paritária, apresentada na Tabela 12.

Todas as comparações foram analisadas e, como se pode observar na Tabela 12, os valores obtidos foram valores menores do que os IR para todos os conjuntos de comparações dos critérios, subcritérios e alternativas. Segundo Saaty (1990), quanto maior for a RC, maior será a inconsistência. Mais especificamente, quando $n=4, \mathrm{RC} \leq 0,09 ; n>4$, $\mathrm{RC} \leq 0,10$. Desta forma, para os critérios do $\mathrm{CD}$ analisado, $n=5, \mathrm{RC}=-0,254$, ou seja, atende ao requisito. Para os subcritérios do $\mathrm{CD}$ analisado, os valores foram $n=6 ; n=3 ; n=7 ; n=6$ e $n=10$, sendo que todos os seus RC são menores que 0,10 . O RC das alternativas também é consistente, pois o número de critérios analisados foram $n=3$ e $\mathrm{RC}=-0,145$, ou seja, $\mathrm{RC} \leq 0,10$. Portanto, qualquer inconsistência nos julgamentos emitidos pelos decisores é aceitável.

$5^{\circ}$ Passo: Para a obtenção dos valores finais de cada alternativa, ou seja, a prioridade composta para as alternativas A, B e C, multiplicou-se a matriz das prioridades agregadas por suas respectivas prioridades relativas. Os resultados são mostrados na Tabela 13, a seguir. 
Tabela 12. Razão de Consistência.

\begin{tabular}{ccccccc}
\hline \multicolumn{7}{c}{ (RC) Razão de Consistência } \\
\hline Critérios & $\begin{array}{c}\text { Subcritérios } \\
\text { Rapidez }\end{array}$ & $\begin{array}{c}\text { Subcritérios } \\
\text { Confiabilidade }\end{array}$ & $\begin{array}{c}\text { Subcritérios } \\
\text { Qualidade }\end{array}$ & $\begin{array}{c}\text { Subcritérios } \\
\text { Flexibilidade }\end{array}$ & $\begin{array}{c}\text { Subcritérios } \\
\text { Custo }\end{array}$ & Alternativas \\
\hline $\mathrm{IR}=1,12$ & $\mathrm{IR}=1,24$ & $\mathrm{IR}=0,58$ & $\mathrm{IR}=1,32$ & $\mathrm{IR}=1,24$ & $\mathrm{IR}=1,48$ & $\mathrm{IR}=0,58$ \\
$-0,254$ & $-0,183$ & $-0,993$ & $-0,328$ & $-0,180$ & $-0,093$ & $-0,145$ \\
\hline
\end{tabular}

Tabela 13. Análise dos Resultados.

\begin{tabular}{ccc}
\hline \multicolumn{3}{c}{ Análise do Resultado } \\
\hline Alternativa A & Alternativa B & Alternativa C \\
\hline 0,077 & 0,185 & 0,754 \\
\hline
\end{tabular}

Observa-se que a melhor alternativa em ordem de prioridade decrescente é a alternativa $\mathrm{C}$, seguida da B e da A. Segundo esta análise, a recomendação dada ao decisor para implementação é a alternativa C. Notou-se que as avaliações do gerente, junto aos supervisores da área, refletiram coerentemente com as condições reais das propostas.

Isto comprova os benefícios do processo $\mathrm{AHP}$ e a sua facilidade de estruturar o processo de tomada de decisão, por meio da elaboração de uma hierarquia de critérios de decisão. Desta forma, os decisores conseguem "enxergar" as alternativas de maneira relativa, aceitando um conjunto de possibilidades de maneira a melhorar o processo de tomada de decisão.

\section{Considerações finais}

É proposta neste artigo uma metodologia capaz de estruturar um CD por intermédio da utilização do processo AHP. A metodologia proposta não busca eliminar os problemas da empresa, mas sim reconhecê-los e tratá-los cientificamente, ou seja, modelá-los. O processo AHP tem como intuito auxiliar os decisores, garantindo qualidade, organização e documentação do processo de análise de decisão, compartilhando o entendimento sobre as questões e, frequentemente, promovendo consenso. O processo indica possíveis alternativas para solução do problema, mas a escolha por uma ou outra compete aos decisores.

$\mathrm{O}$ processo AHP permitiu que o problema fosse estruturado, dividido em critérios, subcritérios e alternativas, definindo as suas possíveis soluções. Esta etapa permitiu que os tomadores de decisão conseguissem definir por meio das suas preferências a melhor solução para o problema. Desta forma, têm sido demonstradas as vantagens da aplicação do processo AHP comparativamente ao procedimento adotado por ocasião da pesquisa. Na definição da melhor alternativa para escolha do $\mathrm{CD}$, os critérios de maior peso foram custo, qualidade e flexibilidade. Assim, o processo forneceu como resultado a alternativa $\mathrm{C}$, como a melhor estrutura para o $\mathrm{CD}$ para a empresa analisada. A escolha desta alternativa foi devido, principalmente, ao fato de que a empresa trabalha com uma grande quantidade de atividades e responsabilidades e necessita de uma estrutura completa e informatizada para gerenciar o CD.

Os resultados alcançados mostram que o objetivo proposto foi atingido, proporcionando melhoria na estruturação e na operacionalização do CD para a empresa do ramo alimentício, quanto à forma de armazenagem, recebimento, movimentação, separação e expedição. Isto mostra que, com o emprego da análise multicritérios, é possível utilizar os julgamentos subjetivos dos decisores envolvidos no processo decisório, com precisão e confiabilidade, conferindo maior confiabilidade e transparência à decisão.

\section{Referências}

Agarwal, A., Shankar, R., \& Tiwari, M. K. (2006). Modeling the metrics of lean, agile and leagile supply chain: an ANP-based approach. European Journal of Operational Research, 173(1), 211-225. http://dx.doi.org/10.1016/j. ejor.2004.12.005.

Belton, V. A., \& Gear, T. (1985). The legitimacy of rank reversal - a comment. Omega, 13(3), 143-144. http:// dx.doi.org/10.1016/0305-0483(85)90052-0.

Bernroider, E., \& Stix, V. (2007). A method using weight restrictions in data envelopment analysis for ranking and validity issues in decision making. Computers \& Operations Research, 34(9), 2637-2647. http://dx.doi. org/10.1016/j.cor.2005.10.005.

Bhushan, N., \& Rai, K. (2004). Strategic decision making. applying the analytic hierarchy process. New York: Springer.

Bond, S. D., Carlson, K. A., \& Keeney, R. L. (2008). Generating objectives: can decision makers articulate what they want? Management Science, 54(1), 56-70. http://dx.doi.org/10.1287/mnsc.1070.0754.

Brans, J. P., Mareshal, B., \& Vincke, P. (1984). PROMÉTHÉE: a new family of outranking methods in multicriteria analysis. In J. P. Brans (Ed.), Operational research (pp. 408-421). Amsterdam: North-Holland.

Chan, F. T. S., Chung, S. H., \& Choy, K. L. (2006). Optimization of order fulfillment in distribution network problems. Journal of Intelligent Manufacturing, 17(3), 307-319. http://dx.doi.org/10.1007/s10845-005-0003-z.

Chatzimouratidis, A. I., \& Pilavachi, P. A. (2009). Technological, economic and sustainability evaluation of power plants using the analytic hierarchy process. 
Energy Policy, 37(3), 778-787. http://dx.doi.org/10.1016/j. enpol.2008.10.009.

Christopher, M. (2011). Logística e gerenciamento da cadeia de suprimentos: criando redes que agregam valor (2. ed.). São Paulo: Cengage Learning.

Cruz, A. T., Jr, \& Carvalho, M. M. (2003). Obtenção da voz do consumidor: estuo de caso em um Hotel Ecológico. Revista Produção, 13(3), 88-100.

Dornier, P. P., Ernst, R., Fernder, M., \& Kouvelis, P. (2011). Logística e operações globais: texto e casos (1. ed.). São Paulo: Atlas.

Henry, M., \& Kato, Y. (2011). An assessment framework based on social perspectives and Analytic Hierarchy Process: a case study on sustainability in the Japanese concrete industry. Journal of Engineering and Technology Management, 28(4), 300-316. http://dx.doi.org/10.1016/j. jengtecman.2011.06.006.

Hou, Y., Wang, B., Ouyang, G., Shen, H., \& He, Y. (2011). An analytic hierarchy process to evaluate pem fuel cell engine performance. International Journal of Hydrogen Energy, 36(11), 6780-6787. http://dx.doi.org/10.1016/j. ijhydene.2011.02.119.

Huijun, S., Ziyou, G., \& Jianjun, W. (2008). A bi-level programming model and solution algorithm for the location of logistics distribution centers. Applied Mathematical Modelling, 32(4), 610-616. http://dx.doi. org/10.1016/j.apm.2007.02.007.

Kueng, P. (2000). Process performance measurement system: a tool to support process-based organizations. Total Quality Management, 11(1), 67-85. http://dx.doi. org/10.1080/0954412007035.

Lee, D. J., \& Hwang, J. (2010). Decision support for selecting exportable nuclear technology using the analytic hierarchy process: a korean case. Energy Policy, 38(1), 161-167. http://dx.doi.org/10.1016/j.enpol.2009.08.069.

Lee, H. H., Yang, T. T., Chen, C. B., \& Chen, Y. L. (2011). A fuzzy hierarchy integral analytic expert decision process in evaluating foreign investment entry mode selection for Taiwanese bio-tech firms. Expert Systems with Applications, 38(4), 3304-3322. http://dx.doi. org/10.1016/j.eswa.2010.08.116.

Lootsma, F. A. (1990). A multiplicative variant of the analytic hierarchy process (Report of the Faculty of Technical Mathematics and Informatics, No. 90-45). Delft: Delft University of Technology.

Lorentz, H. (2008). Production locations for the internationalizing food industry: case study from Russia. British Food Journal, 110(3), 310-334. http://dx.doi. org/10.1108/00070700810858718.

Muralidharan, C., Anantharaman, N., \& Deshmukh, S. G. (2002). A multi-criteria group decision-making model for supplier rating. The Journal of Supply Chain Management, 38(4), 22-33. http://dx.doi.org/10.1111/ j.1745-493X.2002.tb00140.x.
Onut, S., Tuzkaya, U. R., \& Dogac, B. (2008). A particle swarm optimization algorithm for the multiple-level warehouse layout design problem. Computers \& Industrial Engineering, 54(4), 783-799. http://dx.doi. org/10.1016/j.cie.2007.10.012.

Padovani, M., Carvalho, M. M. D., \& Muscat, A. R. N. (2010). Seleção e alocação de recursos em portfólio de projetos: estudo de caso no setor químico. Gestão \& Produção, 17(1), 157-180. http://dx.doi.org/10.1590/ S0104-530X2010000100013.

Passos, A. C., \& Souza, R. C. (2013). Defining a quality index for electric power utilities using multiple criteria decision support and time series analysis. Gestão \& Produção, 20(1), 1-12. http://dx.doi.org/10.1590/ S0104-530X2013000100001.

Rafaeli, L., \& Müller, C. J. (2007). Estruturação de um índice consolidado de desempenho utilizando o AHP. Gestão \& Produção, 4(2), 363-377.

Rao, R. V. (2007). Decision making in the manufacturing environment. London: Springer.

Roy, B. (1986). Classement et choix em présence de points de vue multiples. La méthode Electre, 8, 57-75.

Saaty, T. L. (1990). How to make a decision: the analytic hierarchy process. European Journal of Operational Research, 48(1), 9-26. http://dx.doi.org/10.1016/03772217(90)90057-I.

Saaty, T. L. (2005). Theory and applications of the analytic network process: decision making with benefits, opportunities, costs, and risks. Pittsburgh: RWS Publications.

Schönsleben, P. (2000). Integral logistics management: planning and control of comprehensive business processes. Boca Raton: St. Lucie Press.

Triantaphyllou, E., \& Mann, S. H. (1995). Using the analytic hierarchy process for decision making in engineering applications: some challenges. International Journal of Industrial Engineering: Applications and Practice, 2(1), 35-44.

Vieira, J. G. V., Yoshizaki, H. T. Y., \& Ho, L. L. (2009). Um estudo sobre colaboração logística entre indústria de bens de consumo e redes de varejo supermercadista. Gestão \& Produção, 16(4), 556-570. http://dx.doi. org/10.1590/S0104-530X2009000400006.

Wang, L., Chu, J., \& Wu, J. (2007). Selection of optimum maintenance strategies based on a fuzzy analytic hierarchy process. International Journal of Production Economics, 107(1), 151-163. http://dx.doi.org/10.1016/j. ijpe.2006.08.005.

Watson, S. R., \& Freeling, A. N. S. (1982). Assessing attribute weights by ratios. Omega, 10(6), 582-583. http://dx.doi.org/10.1016/0305-0483(82)90061-5.

Yang, M., Khan, F. I., \& Sadiq, R. (2011). Prioritization of environmental issues in offshore oil and gas operations: 
a hybrid approach using fuzzy inference system and fuzzy analytic hierarchy process. Process Safety and Environmental Protection, 89(1), 22-34. http://dx.doi. org/10.1016/j.psep.2010.08.006.

Yi, G., \& Dan, Z. (2009). Analysis on the distribution centre location based on TOPSIS/DEA/AHP. Journal of Chongqing Institute of Technology, 23(11), 76-80.
Zhen-Zhong, W. (2010). Investigation and application of analytic hierarchy process in the selecting of address of the distribution center. Logistics Engineering and Management, 1, 97-100.

Zhi-Cheng, Z., \& Xin, L. (2009). Research on the location problem of cold chain logistics distribution centers based on AHP method and grey relational degree. Science Technology and Engineering, 5, 268-271. 